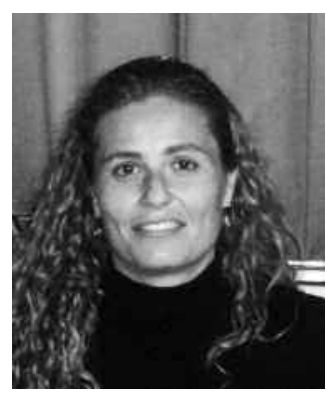

\title{
Teriparatide for Glucocorticoid-induced Osteoporosis
}

Efficacy trials have been widely considered to rank at the highest level of published evidence. Although this is certainly a major advance in the field of clinical research, results of clinical trials have some important limitations when applied to everyday patients. Besides the fact that the studied population does not necessarily behave in a similar fashion across different countries, races, practices, or healthcare systems ${ }^{1}$, the population included in such trials has usually been carefully selected to assess individuals as "cleanly" as possible with respect to the disease and outcomes as defined in the study design. However, in clinical practice, in the vast majority of cases patients suffer from other diseases, receive other drugs, and adhere to treatments very differently. It has been estimated that up to $80 \%$ of patients asking for osteoporosis care would be excluded from osteoporosis trials ${ }^{2}$. Hence the importance of well designed observational studies where patients, interventions, and results are identical to what we deal with in our everyday practice. Only pragmatic or naturalistic studies can overcome the gap between efficacy and effectiveness.

Teriparatide is a drug that is better known thanks to observational studies. It was approved for postmenopausal osteoporosis after a phase 3 randomized clinical trial ${ }^{3}$ that, for several reasons, was stopped after about 2 years. Later, other randomized trials have supported its use in men ${ }^{4}$ and in glucocorticoid (GC)-induced osteoporosis ${ }^{5}$. Nevertheless, some important questions were raised after the use of the drug became widespread. Some authors suggested a blunting effect when the drug was used in combination or after treatment with strong antiresorptives ${ }^{6}$. This important issue for the practicing clinician has been explored precisely by a large observational trial, EUROFORS (European Study of Forsteo) $)^{7,8,9}$, and similarly by EFOS (European Forsteo Observational Study), from Karras, et al and reported in this issue of The Journal ${ }^{10}$. Data obtained by clinicians from several European countries demonstrate a lack of a blunting effect and full efficacy of the drug even in patients receiving longterm treatment with other antiosteoporosis drugs. This clarification has been instrumental, since a large number of patients with osteoporosis have received previous treatment with antiresorptives and, in particular, with aminobisphosphonates. Therefore, the validity of these results supports our decisions in cases where the period of treatment with a bisphosphonate has been completed, the patient is still at high risk of fracture, but we do not want to continue treatment. Also, in cases where an antiresorptive is not achieving the desired effect and the patient shows inadequate response to the drug ${ }^{11}$, the need for an anabolic is the main option. Because of all these situations we now have solid evidence in favor of the efficacy of the treatment.

GC-induced osteoporosis is very difficult territory to explore in randomized clinical trials. The negative bone effect induced by these compounds is particularly aggressive $\mathrm{e}^{12}$ and constitutes the main cause of secondary osteoporosis and associated fractures, even at low doses ${ }^{13}$. However, patients receive GC for a large variety of diseases, at very different doses, continuously or in an intermittent fashion, with diverse compounds and in dissimilar regimes and modes of administration. Moreover, a placebo arm is unacceptable for included study subjects. This makes it extremely problematic to form homogeneous groups in which to study the effect of an antiosteoporosis treatment. Teriparatide has demonstrated antifracture efficacy in this clinical situation in a well designed comparator trial versus alendronate ${ }^{5}$. However, the main limitations of these data in terms of external validity leave some questions open when results are translated to the usual patient in routine practice.

This is the main value of the EFOS study ${ }^{10}$. Carried out in 8 European countries, it included patients about to start teriparatide under clinical conditions of usual practice. Among included cases, a subgroup of GC users was the focus of the reported analysis. Obviously, these cases had more severe concomitant diseases, received more concomitant medications, and had a worse functional status and health-related quality of life: in other words, the usual patients treated with GC and therefore at significant high

See Teriparatide in postmenopausal women with osteoporosis and GC use, page 600

Personal non-commercial use only. The Journal of Rheumatology Copyright $@$ $\odot 2012$. All rights reserved. 
risk of fracture. However, in addition, they were at high risk of inadequate response to treatments for osteoporosis ${ }^{14}$.

Perhaps the most relevant result of the work of Karras, et $a l^{10}$ is new evidence added to the sequential therapy approach in patients receiving GC. Analysis of their results supports the antifracture efficacy of the treatment, even after stopping teriparatide, when a continuation therapy is used. Patients also reported better health-related quality of life scores and back pain relief. No treatment can be followed up for life, and these strategies, although widely used in clinical practice, need to be fully confirmed by efficacy and effectiveness trials. The gain in terms of bone density, bone strength, and fracture reduction obtained by a full course of teriparatide treatment can vanish in a few months after therapy has ended.

Drawing a parallel between osteoporosis and hematological disorders, with teriparatide we might induce a "remission" of the disease that, later on, will be followed by a phase of "consolidation" when an antiresorptive is used. Whether this cycle of treatment can be repeated several times to reverse anatomical deterioration in the bone, both in terms of density and quality, remains to be proved but, theoretically, it could lead to a "cure" of the disease. Every anabolic-antiresorptive cycle will set up a new level of mechanical strength, given that currently available therapies show a "therapeutic ceiling" 14 beyond which the restoration of bone competence cannot be achieved. It is especially true in cases with advanced disease, and precisely such cases are in greater need of a fully effective treatment.

One of the best examples of the need for a cure for osteoporosis is when it is induced by the aggressive effects of glucocorticoids on bone.

\author{
ADOLFO DIEZ-PEREZ, MD; \\ EMILIA SOLE, MD, \\ Department of Internal Medicine, \\ Hospital del Mar-IMIM, \\ Autonomous University of Barcelona, \\ P. Maritim 25-29, \\ 08003 Barcelona, Spain
}

Address correspondence to Dr. Díez-Pérez;

E-mail: ADiez@parcdesalutmar.cat

\section{REFERENCES}

1. Díez-Pérez A, Hooven FH, Adachi JD, Adami S, Anderson FA, Boonen $\mathrm{S}$, et al. Regional differences in treatment for osteoporosis. The Global Longitudinal Study of Osteoporosis in Women (GLOW). Bone 2011;49:493-8.
2. Dowd R, Recker RR, Heaney RP. Study subjects and ordinary patients. Osteoporos Int 2000;11:533-6.

3. Neer RM, Arnaud CD, Zanchetta JR, Prince R, Gaich GA, Reginster JY, et al. Effect of parathyroid hormone (1-34) on fractures and bone mineral density in postmenopausal women with osteoporosis. N Engl J Med 2001;344:1434-41.

4. Orwoll ES, Scheele WH, Paul S, Adami S, Syversen U, Diez-Perez A, et al. The effect of teriparatide [human parathyroid hormone (1-34)] therapy on bone density in men with osteoporosis. J Bone Miner Res 2003;18:9-17.

5. Saag KG, Shane E, Boonen S, Marín F, Donley DW, Taylor KA, et al. Teriparatide or alendronate in glucocorticoid-induced osteoporosis. N Engl J Med 2007;357:2028-39.

6. Finkelstein JS, Hayes A, Hunzelman JL, Wyland JJ, Lee H, Neer $\mathrm{RM}$. The effects of parathyroid hormone, alendronate, or both in men with osteoporosis. N Engl J Med 2003;349:1216-26.

7. Eastell R, Nickelsen T, Marin F, Barker C, Hadji P, Farrerons J, et al. Sequential treatment of severe postmenopausal osteoporosis after teriparatide: Final results of the randomized, controlled European Study of Forsteo (EUROFORS). J Bone Miner Res 2009;24:726-36.

8. Obermayer-Pietsch BM, Marin F, McCloskey EV, Hadji P, Farrerons J, Boonen S, et al. Effects of two years of daily teriparatide treatment on BMD in postmenopausal women with severe osteoporosis with and without prior antiresorptive treatment. J Bone Miner Res 2008;23:1591-600.

9. Boonen S, Marin F, Obermayer-Pietsch B, Simões ME, Barker C, Glass EV. Effects of previous antiresorptive therapy on the bone mineral density response to two years of teriparatide treatment in postmenopausal women with osteoporosis. J Clin Endocrinol Metab 2008;93:852-60.

10. Karras D, Stoykov I, Lems WF, Langdahl BL, Ljunggren O, Barret A, et al. Effectiveness of teriparatide in postmenopausal women with osteoporosis and glucocorticoid use: 3-year results from the European Forsteo Observational Study (EFOS). J Rheumatol 2012;39:600-9.

11. Díez-Pérez A, González-Macías J. Inadequate responders to osteoporosis treatment: Proposal for an operational definition. Osteoporos Int 2008;19:1511-6.

12. Canalis E, Mazzioti G, Giustina A, Bilezikian JP. Glucocorticoid-induced osteoporosis: Pathophysiology and therapy. Osteoporos Int 2007;18:1319-28.

13. Van Staa TF, Leufkens HGM, Abenhaim L, Zhang B, Cooper C. Use of oral costicosteroids and risk of fractures. J Bone Miner Res 2000; 15:993-1000

14. Díez-Pérez A, Olmos JM, Nogués X, Sosa M, Díaz-Curiel M, Pérez-Castrillón JL, et al. Risk factors for prediction of inadequate response to antiresorptives. J Bone Miner Res 2011 Dec 8. [Epub ahead of print]

J Rheumatol 2012;39:461-2; doi:10.3899/jrheum.111629 